\title{
Cassava Brown Streak Disease and Ugandan cassava brown streak virus Reported for the First Time in Zambia
}

Rabson M. Mulenga, Zambia Agriculture Research Institute, Mount Makulu Central Research Station, Chilanga, Lusaka, Zambia; Laura M. Boykin, The University of Western Australia, ARC Centre of Excellence in Plant Energy Biology and Molecular Sciences, Crawley, Perth 6009, Western Australia, Australia; Patrick C. Chikoti, Suwilanji Sichilima, and Dickson Ng'uni, Zambia Agriculture Research Institute, Mount Makulu Central Research Station; and Olufemi J. Alabi, ${ }^{\dagger}$ Department of Plant Pathology \& Microbiology, Texas A\&M AgriLife Research and Extension Center, Weslaco 78596

\begin{abstract}
A diagnostic survey was conducted in July 2017 in two northern districts of Zambia to investigate presence or absence of cassava brown streak disease (CBSD) and its causal viruses. In total, 29 cassava fields were surveyed and cassava leaf samples were collected from 116 plants (92 symptomatic and 24 nonsymptomatic). CBSD prevalence was approximately $79 \%$ (23 of 29) across fields. Mean CBSD incidence varied across fields but averaged $32.3 \%$ while mean disease severity was 2.3 on a 1-to-5 rating scale. Reverse-transcription polymerase chain reaction screening of all 116 samples with one generic and two speciesspecific primer pairs yielded DNA bands of the expected sizes from all symptomatic plants with the generic $(785 \mathrm{bp})$ and Ugandan cassava brown streak virus (UCBSV)-specific (440 bp) primers. All 24

nonsymptomatic samples were negative for UCBSV and all samples tested negative with primers targeting Cassava brown streak virus. The complete genome of a representative isolate of UCBSV (WP282) was determined to be 9,050 nucleotides in length, minus the poly A tail A comparative analysis of this isolate with global virus isolates revealed its nature as a sequence variant of UCBSV sharing 94 and $96 \%$ maximum complete polyprotein nucleotide and amino acid identities, respectively, with isolates from Malawi (MF379362) and Tanzania (FJ039520). This is the first report of CBSD and UCBSV in Zambia, thus expanding the geographical distribution of the disease and its causal virus and further reinforcing the need to strengthen national and regional phytosanitary programs in Africa.
\end{abstract}

Cassava brown streak disease (CBSD) and cassava mosaic disease (CMD) are major constraints to cassava (Manihot esculenta Crantz) production in sub-Saharan Africa. Both diseases produce distinct symptoms in cassava. CMD and CBSD causal viruses are transmitted by the whitefly Bemisia tabaci (Gennadius) in persistent and semipersistent manners, respectively. However, in a recent study, the DAG motif associated with aphid transmission of potyviruses was found within coat protein (CP) genes of Cassava brown streak virus (CBSV) genomes and two other ipomoviruses, suggestive of their potential aphid transmissibility (Ateka et al. 2017). Whereas CMD and its causal viruses have been the subject of intensive studies (Alabi et al. 2015; Thottappilly et al. 2003), the body of knowledge on CBSD and its causal viruses is just beginning to evolve (Legg et al. 2015).

First described in 1936 in the coastal area of Tanzania (Storey 1936), CBSD is now known to be caused by two positive-sense single-stranded RNA viruses; namely, CBSV and Ugandan cassava brown streak virus (UCBSV) that belong to the genus Ipomovirus in the family Potyviridae (Mbanzibwa et al. 2009; Winter et al.

${ }^{\dagger}$ Corresponding author: O. J. Alabi; E-mail alabi@tamu.edu

Funding: This project was supported with funds from the Agricultural Productivity Program for Southern Africa (APPSA) Zambia, awarded to Zambia Agriculture Research Institute, grant number P094183-IDA52050 (subproject: CV-P01-2016). Travel funds for R. Mulenga's visit to the Texas A\&M AgriLife Research and Extension Center, Weslaco facility, were provided by the Norman E. Borlaug Leadership Enhancement in Agriculture Program (Borlaug-LEAP) funded by, USAID. Computational resources provided by the Pawsey Supercomputing Centre with funding from the Australian Government and the Government of Western Australia supported this work.

*The $\boldsymbol{e}$-Xtra logo stands for "electronic extra" and indicates that one supplementary table is published online.

Accepted for publication 5 February 2018.

(C) 2018 The American Phytopathological Society
2010). The genome organization of both viruses is similar, comprising a large polyprotein that encodes 10 genes but lacks the helper component proteinase (Winter et al. 2010) present in most members of the family Potyviridae, including in Sweet potato mild mottle virus, the typical Ipomovirus sp. (Tugume et al. 2010). Rather, both viruses encode a unique HAM1 protein thought to be of cellular origin (Mbanzibwa et al. 2009). In cassava, CBSD symptoms due to either virus are largely indistinguishable from each other, although foliar symptoms due to UCBSV are reported to be milder than those induced by CBSV (Patil et al. 2011; Winter et al. 2010). It is unclear whether such phenotypic differences are due to virus- or hostdependent factors, the environment, or their interactions. However, CBSV isolates are more genetically diverse than UCBSV isolates, and intraspecies but not interspecies recombination has been reported for both viruses (Alicai et al. 2016; Mbanzibwa et al. 2009; Ndunguru et al. 2015). Countrywide surveys have shown that UCBSV is more widespread than CBSV, with confirmed reports of the former virus in eight countries compared with that of the latter in four countries (Legg et al. 2015). Additional reports exist of the presence of CBSD in several other sub-Saharan African countries such as Angola, Gabon, and Madagascar but the association of either or both viruses with these occurrences is yet to be determined (Legg et al. 2015). In addition, CBSV has been shown to have a faster rate of evolution compared with UCBSV (Alicai et al. 2016).

The landlocked country of Zambia is bordered to the north by the Democratic Republic of Congo, to the west by Angola, to the east by Malawi and Mozambique, and to the south by Zimbabwe, Botswana, and Namibia. Thus far, there are confirmed reports of UCBSV in the Democratic Republic of Congo (Mulimbi et al. 2012) and Malawi (Mbewe et al. 2015; Nichols 1950) and of CBSV in Mozambique (Hillocks et al. 2002) and Malawi (Mbewe et al. 2015; Nichols 1950). These reports heightened concerns of CBSD spread into Zambia due to the risks of inadvertent introductions via transborder movement of contaminated cassava cuttings. Hence, survey efforts were initiated in 2009 to determine the incidence and distribution of CBSD, CMD, and their causal viruses in the seven major cassava-growing provinces of Zambia. These efforts led to the detection and characterization of CMD causal viruses in farmers' fields 
across the seven cassava-growing provinces (Chikoti et al. 2013, 2015; Mulenga et al. 2016) but CBSD was reported to be absent (Chikoti et al. 2013, 2015). Although areas along the long border of Zambia with Malawi were extensively surveyed, the extreme north of Luapula and Northern provinces covering Chienge and Kaputa districts that border the Democratic Republic of Congo were not covered. Villages and other human settlements in both districts are populated with people of mixed citizenry and it is not uncommon for cassava farmers across these largely unmanned border areas to exchange vegetative cuttings. Therefore, an intensive survey was conducted in farmers' fields located in the extreme north of Luapula and Northern provinces to determine the presence or absence of CBSD and its causal viruses.

\section{Materials and Methods}

Survey and sample collection. The survey was conducted in July 2017 in the extreme northern part of Zambia covering the districts of Chienge in Luapula province and Kaputa in Northern province (Fig. 1). The two districts lie on the border with the Democratic Republic of Congo, with no physical barrier between the two countries. Both districts were not covered in previous surveys (Chikoti et al. 2013, 2015; Mulenga et al. 2016) due to challenges associated with their accessibility. Surveys were conducted in the agriculture camps of Mwabu (4 fields), Chienge central (5 fields), and Chipungu (4 fields) in Chienge district (13 fields) and Chocha (2 fields), Kaputa central (7 fields), Chipili (3 fields), and Kasepa (4 fields) in Kaputa district (16 fields). Cassava fields were surveyed along secondary and feeder roads encompassing areas along Lakes Mweru and Mweru Wantipa that lie at altitudes of approximately $940 \mathrm{~m}$ above sea level (Fig. 1). In total, 29 cassava fields were assessed across both districts at 5- to $10-\mathrm{km}$ intervals and each field was georeferenced using a handheld global positioning systems device (Garmin International Inc., Olathe, KS). CBSD incidence was assessed for each field as a proportion of cassava plants showing characteristic foliar or stem brown streak symptoms (Fig. 2) out of a total of 30 visually inspected plants along two diagonals (15 plants per diagonal) (Sseruwagi et al. 2004). Disease severity was assessed on a scale of 1 to 5 (Rwegasira et al. 2011). Mean incidence and severity were calculated along field diagonals for each camp and district regardless of the cultivar. To confirm root and stem diagnostic symptoms, four plants per field with foliar symptoms were uprooted, sliced, and inspected for presence of root necrosis (Fig. 2G) while stems with brown streak-like symptoms (Fig. 2F) were sliced from the node upward. Symptomatic leaf samples (Fig. $2 \mathrm{~A}$ to E) were collected individually from four plants per field and preserved dry, as per Rajabu (2013). In total, 116 (symptomatic = 92 and nonsymptomatic $=24$ ) samples were collected during the survey. All samples were packaged in labeled envelops and transported to the Mount Makulu Central Research Station, Chilanga, Lusaka, Zambia for analysis.

RNA extraction. RNA was extracted from each dried cassava leaf sample using a previously described cetyltrimethylammonium bromide (CTAB) protocol (Alicai et al. 2016). Briefly, $50 \mathrm{mg}$ of leaf tissue per sample was ground in $1 \mathrm{ml}$ of CTAB extraction buffer containing 2\% (wt/vol) CTAB, 2\% PVP-40, $100 \mathrm{mM}$ Tris- $\mathrm{HCl}$ (pH 8.0), 25 mM EDTA, $2 \mathrm{M} \mathrm{NaCl}$, and $2 \%$ mercaptoethanol (added immediately before use). Approximately $750 \mu \mathrm{l}$ of the extract was pipetted into clean 2-ml microcentrifuge tubes and incubated in a water bath at $65^{\circ} \mathrm{C}$ for $15 \mathrm{~min}$, then cooled at room temperature. An equal volume of chloroform-isoamyl alcohol $(24: 1$, vol/vol) was added to the extract and tubes were vortexed until content turned cloudy, followed by centrifugation at $12,000 \mathrm{rpm}$ for $15 \mathrm{~min}$. This step was repeated twice. Finally, $600 \mu \mathrm{l}$ of extract was transferred into a $1.5-\mathrm{ml}$ microcentrifuge tube to which one-third volume of icecold isopropanol was added, followed by incubation at $-20^{\circ} \mathrm{C}$ for $1 \mathrm{~h}$ The tubes were then centrifuged at $13,000 \mathrm{rpm}$ for $30 \mathrm{~min}$ at $4{ }^{\circ} \mathrm{C}$. The pellets were washed twice with $70 \%$ ethanol and air dried at room temperature. The dried pellet was dissolved in $50 \mu \mathrm{l}$ of diethyl pyrocarbonate-treated water, analyzed on a NanoDrop 2000

\section{Disease distribution}
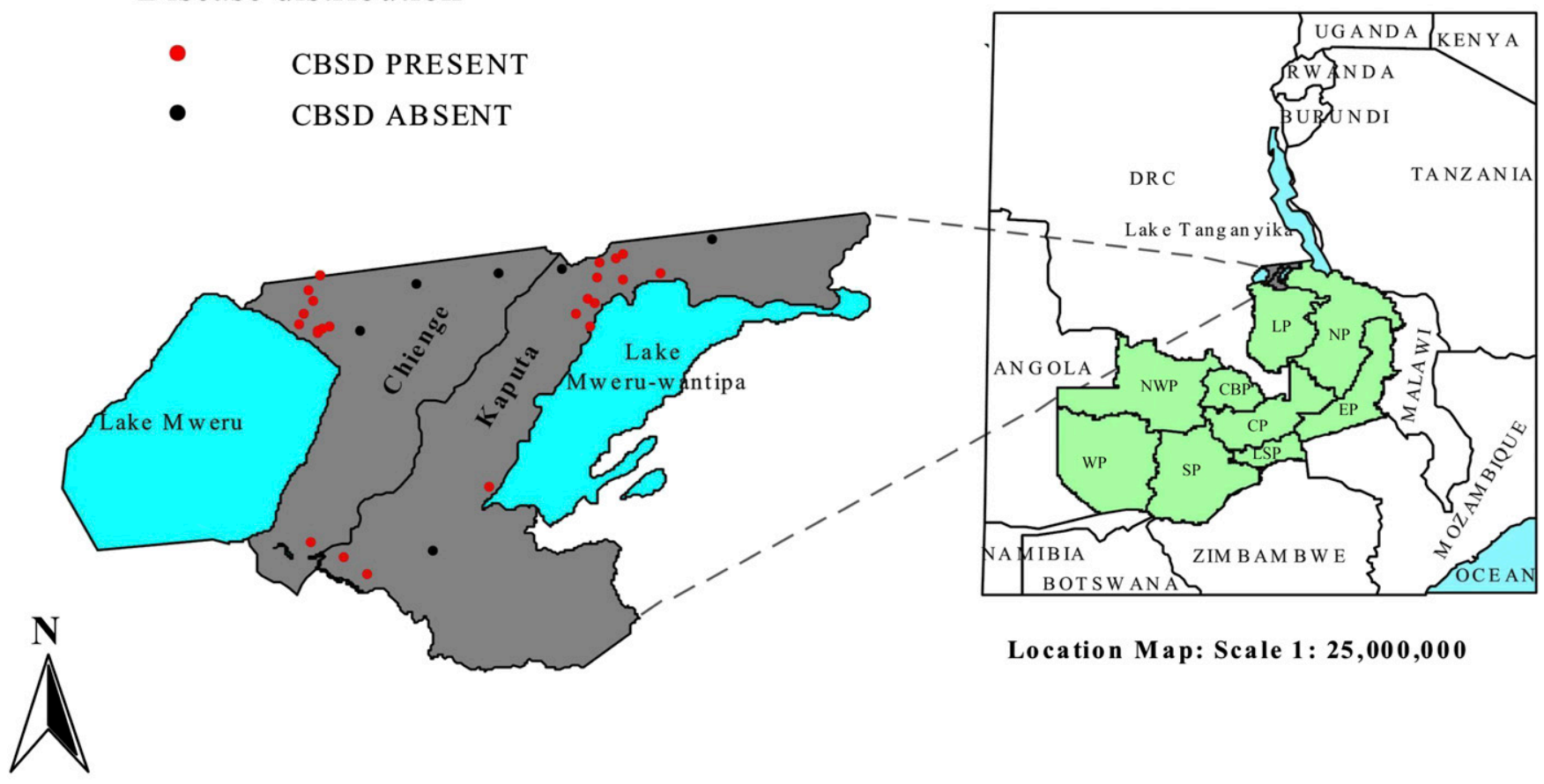

Location Map: Scale 1: 25,000,000

Scale 1: 500,000

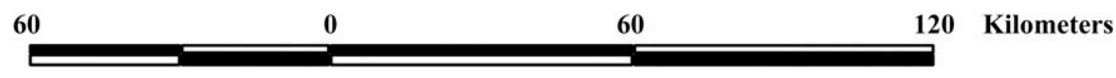

Fig. 1. Partial map of Africa showing Zambia and adjoining countries and survey locations targeted in this study: Chienge and Kaputa districts of Luapula and Northern provinces of Zambia. Light and dark dots denote cassava fields with and without cassava brown streak disease (CBSD) symptoms, respectively. LP = Luapula province, LSP = Lusaka province, $\mathrm{EP}=$ Eastern province, $\mathrm{NP}=$ Northern province, $\mathrm{CBP}=$ Copperbelt province, $\mathrm{CP}=$ Central province, $\mathrm{WP}=\mathrm{Western}$ province, $\mathrm{SP}=\mathrm{Southern}$ province, and NWP $=\mathrm{Northwestern}$ province. 
series spectrophotometer (Thermo Fisher Scientific Inc., Waltham, MA) and stored at $-20^{\circ} \mathrm{C}$ until use.

cDNA synthesis and polymerase chain reaction. Total RNA ( $2 \mu \mathrm{g}$ per sample) was subjected to cDNA synthesis using the Revert Aid First Strand cDNA synthesis kit (Thermo Fisher Scientific Inc.) according to the manufacturer's protocol. Approximately $400 \mathrm{ng}$ of cDNA per sample was used in a $25-\mu 1$ polymerase chain reaction (PCR) volume containing $1 \times$ DreamTaq Buffer (Life Technologies, Carlsbad, CA), $0.2 \mathrm{mM}$ dNTP, $0.2 \mathrm{mM}$ each sense and antisense primers, and $1 \mathrm{U}$ of DreamTaq DNA polymerase. Each of the 116 samples was screened with generic primers CPBSV1 and CPBSV2 (Rajabu 2013) and species-specific primers, CBSVF2/CBSVR7 and CBSVF2/CBSVR8 (Abarshi et al. 2012) capable of discriminating between CBSV and UCBSV, respectively. Cycling conditions were initial denaturation at $94^{\circ} \mathrm{C}$ for $3 \mathrm{~min}$; followed by 35 cycles of $94^{\circ} \mathrm{C}$ for $30 \mathrm{~s}, 52^{\circ} \mathrm{C}$ for $30 \mathrm{~s}$, and $72^{\circ} \mathrm{C}$ for $45 \mathrm{~s}$; with a final extension step of $72^{\circ} \mathrm{C}$ for $5 \mathrm{~min}$. Additionally, each sample was screened for the presence of African cassava mosaic virus (ACMV) and East African cassava mosaic virus (EACMV), two CMD causal viruses known to be prevalent across cassava fields in Zambia (Chikoti et al. 2015; Mulenga et al. 2016). The ACMV-specific primers JSP01 and -02 (Pita et al. 2001) and EACMV-specific primers EAB555F and -R (Ndunguru et al. 2005) were employed for this purpose. The PCR products were electrophoresed in $1 \%$ agarose gel prestained with ethidium bromide at $10 \mathrm{mg} / \mathrm{ml}$ in $1 \times$ Tris-acetate-EDTA buffer and visualized using a Gel Doc XR System (Bio-Rad Laboratories, Hercules, CA). An aliquot of the O'GeneRuler 1-kb DNA Ladder (Thermo Fisher Scientific Inc.) was loaded alongside PCR amplicons for size verification.

Complete genome amplification and characterization of UCBSV. Based on results of initial screening of the 116 fieldcollected samples, dried leaf tissues from a representative isolate (WP282) that gave DNA amplicons of the expected size with one of the primer pairs was shipped under a United States Department of Agriculture Animal and Plant Health Inspection Service Plant Protection and Quarantine permit to the Texas A\&M AgriLife Research and Extension Center, Weslaco facility for further molecular characterization. Total nucleic acid was extracted from isolate WP282 using a Spectrum Plant total RNA Kit (Sigma-Aldrich, St. Louis) and used for cDNA synthesis with the cDNA synthesis Kit, ThermoScript RTPCR System (Thermo Fisher Scientific, Inc.), as per the manufacturer's instructions. The genome of the CBSD causal virus present in isolate WP282 was amplified as four pieces of overlapping DNA fragments using newly designed primers (Table 1) derived based on a consensus sequence of virus isolates available in GenBank (Supplementary Table S1). The 25- $\mu$ l PCR volume for each primer pair consisted of $1 \times$ PrimeSTAR GXL buffer, $0.2 \mathrm{mM}$ dNTP, primers at $0.2 \mu \mathrm{M}$ each, $1.5 \mathrm{U}$ of PrimeSTAR GXL DNA polymerase (Takara-Bio USA, Inc., Mountain View, CA), and $2 \mu$ l of a 1:10 dilution of the template cDNA. Thermal cycling conditions were 35 cycles of $98^{\circ} \mathrm{C}$ for $10 \mathrm{~s}$, annealing at $55^{\circ} \mathrm{C}$ for $15 \mathrm{~s}$, and extension $68^{\circ} \mathrm{C}$ for $1 \mathrm{~min} / \mathrm{kb}$. Correct size amplicons on a prestained (ethidium bromide at $10 \mathrm{mg} / \mathrm{ml}$ ) $1 \%$ agarose gel were excised and gel eluted using the Zymoclean Gel DNA recovery kit (Zymo Research Corp., Irvine, CA). The eluate was A-tailed and cloned into a pCR2.1 TOPO-TA vector, then transformed into One Shot TOPO10 Escherichia coli chemically competent cells, according to the manufacturer's protocol (Life Technologies). Two plasmids with the correct size inserts per DNA amplicon were recovered using a GenElute Plasmid Miniprep Kit (Sigma-Aldrich) and initially sequenced in both directions with the $\mathrm{M} 13 \mathrm{~F}$ and $-\mathrm{R}$ primers. Additional primers were used to walk each plasmid DNA sample (data not shown). A consensus sequence was obtained for each PCR fragment and the putative fulllength viral genome was assembled using the CAP contig assembly program of the BioEdit software (Hall 1999). The genome sequence obtained from isolate WP282 was annotated based on homologies with corresponding sequences in GenBank.
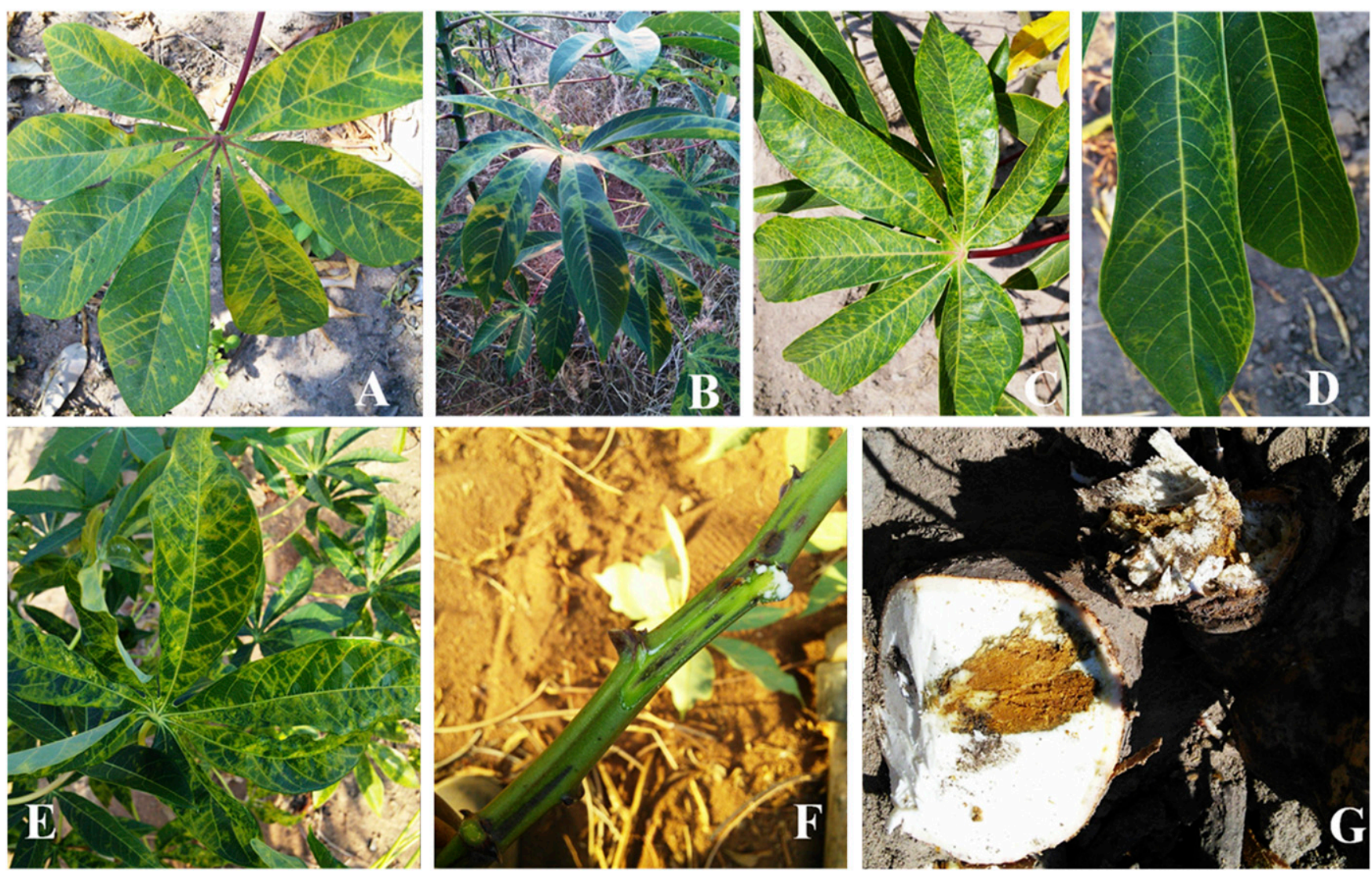

Fig. 2. Symptoms of cassava brown streak disease (CBSD) observed on naturally infected cassava plants in Chienge (Luapula province) and Kaputa (Northern province) districts of Zambia. The observed foliar symptoms include chlorotic blotches (A and $\mathbf{B})$, mottling $(\mathbf{C})$, and feathery vein chlorosis $(\mathbf{D}$ and $\mathbf{E})$. Severely affected plants may also show brown streaks on stems (F) and root necrosis (G). In addition to CBSD symptoms, few plants also displayed symptoms of mosaic and leaf distortion typical of cassava mosaic disease (E). 
Sequence analysis. The complete polyprotein and gene-specific sequences of isolate WP282 were compared with corresponding GenBank sequences. Sequence alignments were generated with the MUSCLE alignment program (https://www.ebi.ac.uk/Tools/msa/ muscle/) and the alignment files employed for calculating pairwise sequence identity matrices with the BioEdit program (Hall 1999). The Simplot program, v.3.5.1 (Lole et al. 1999) was used to depict a graphical representation of genome-wide sequence comparisons between isolate WP282 and selected GenBank virus isolates. The phylogenetic relationship between isolate WP282 and publicly available complete genome GenBank isolates of CBSV $(n=14)$ and UCBSV $(n=19)$, including infectious clones of UCBSV, was inferred using Bayesian analyses conducted with ExaBayes, v.1.4.1 (Aberer et al. 2014), as described by Ndunguru et al. (2015). The polyprotein alignment file involving only UCBSV isolates was scanned for the presence of reticulate phylogenetic networks using the Neighbor-Net method as implemented in SplitsTree, v4.10 (Huson and Bryant 2006). The detection of reticulate networks involving isolate WP282 rather than a tree-like topology will indicate that its evolutionary history has been shaped by recombination (Alabi et al. 2011; Huson and Bryant 2006), as reported for CBSD causal viruses (Alicai et al. 2016; Mbanzibwa et al. 2011; Ndunguru et al. 2015). The exact nature of any potential recombination event was then investigated using the RDP4 software (Martin et al. 2015).

\section{Results}

CBSD symptoms and prevalence. Characteristic CBSD symptoms were observed in farmers' fields in the seven agriculture camps located in Chienge $(n=3)$ and Kaputa $(n=4)$ districts. The cassava landraces commonly encountered across the 29 surveyed fields were Nshile, Kalulundyongo, Ndelekulwa, Chibungabunga, and Kalilanshindo. In addition, a cassava cultivar referred to as "Research", presumably denoting that it was received from a research institute, was encountered in one field in Chienge district. Although diverse CBSD symptoms were observed on these cultivars (Fig. 2), leaf chlorotic blotching (Fig. 2A and B) was the most common symptom on landraces Nshile, Kalulundyongo, and Ndelekulwa, whereas Chibungabunga and Kalilanshindo displayed feathery veinal yellowing (Fig. $2 \mathrm{D}$ and $\mathrm{E})$. Of the 13 fields surveyed in Chienge district, approximately $77 \%$ (10 of 13) had CBSD with disease incidence recorded of 10 to $100 \%$ and district-wide mean incidence of approximately $35 \%$ (Table 2). Similarly, approximately $81 \%$ (13 of 16) of fields surveyed in Kaputa district had CBSD, with disease incidence recorded of 3 to $67 \%$ and district-wide mean incidence of $30 \%$ (Table 2). Overall CBSD prevalence across fields visited in both districts was approximately $79 \%$ (23 of 29). Moderate CBSD symptoms were observed across the 23 CBSD-affected fields regardless of the cassava

Table 1. Oligonucleotides used for amplification of complete genome of Ugandan cassava brown streak virus (UCBSV) isolate WP282 from Zambia (MG257787)

\begin{tabular}{llc}
\hline Name $^{\mathbf{a}}$ & \multicolumn{1}{c}{ Sequence $\left(\mathbf{5}^{\prime} \mathbf{- 3}^{\prime}\right)^{\mathbf{b}}$} & Size (bp) \\
\hline UCBSVv1 & AAAAATCACATACTCATgACATAA & 549 \\
UCBSVc549 & gCTgTAgCCTTCgTTCTAC & $\ldots$ \\
UCBSVv502 & AgTYgCTTgTgCCTTTg & 2,681 \\
UCBSVc3182 & CAAgggTAACACCATTTTC & $\ldots$ \\
UCBSVv2945 & ggAACATCTgTgTTTggTgATg & 3,619 \\
UCBSVc6563 & CTTCACTTTCCATTACAgCCTTg & $\ldots$ \\
UCBSVv6456 & CTAAgAAGCACCgTggAAAT & 2,600 \\
UCBSVc9055 & CTACACCRAACARAAggATATg & $\ldots$ \\
\hline
\end{tabular}

${ }^{\mathrm{a}}$ Lowercase letters $\mathrm{v}$ and $\mathrm{c}$ indicate virion and complementary sense primers, respectively. Numerals following both symbols indicate genome position of the starting nucleotide for each primer based on isolate WP282.

${ }^{\mathrm{b}} \mathrm{Y}=\mathrm{C}+\mathrm{T}, \mathrm{R}=\mathrm{A}+\mathrm{G}, \mathrm{D}=\mathrm{G}+\mathrm{A}+\mathrm{T}, \mathrm{M}=\mathrm{A}+\mathrm{C}$, and $\mathrm{W}=\mathrm{A}+\mathrm{T}$. Primer pairs UCBSVv502/UCBSVc3182 and UCBSVv6456/UCBSVc9055 were designed based on consensus sequence of alignments derived from 17 GenBank isolates while the remaining two primer pairs are specific to isolate WP282. cultivar, with a mean severity score of 2.3 (range $=2$ to 3.5 ). Characteristic CBSD root (Fig. 2G) and stem (Fig. 2F) symptoms were also observed on few plants in a limited number of locations (Table 2). In these locations, incidence of typical CBSD stem symptoms (Fig. 2F) ranged from 2.2 to $10 \%$ (low) and mean severity of root necrosis ranged from 2 to 2.3 (mild to moderate) (Table 2). Interestingly, a few plants (Chienge $=2$ and Kaputa $=3$ ) showed symptoms of both CBSD and CMD, suggesting mixed infections of causal viruses of both diseases in these samples. Based on these results, leaf tissue samples taken from all 116 plants (symptomatic $=92$ and nonsymptomatic $=24$ ) were screened for presence of CBSD and CMD causal viruses.

Reverse-transcription PCR analyses of samples. The pair of generic CPBSV1 and -2 primers (Rajabu 2013) produced the expected 785-bp amplicon from all 92 symptomatic samples, whereas all 24 nonsymptomatic samples were negative. This indicated that each of the 92 symptomatic samples was positive for at least one of the two CBSD causal viruses. Further analysis of these 92 samples with virus-specific primers resulted in the amplification of the expected 440-bp UCBSV-specific DNA fragment from all 92 samples with the primer pair CBSVF2/CBSVR8. No DNA band was obtained from all 92 samples with the CBSV-specific primers CBSVF2 and CBSVR7, indicating that UCBSV is the only CBSD causal virus present in these samples. Additionally, 5 (5.4\%) of the 92 UCBSVpositive samples also tested positive for ACMV (4 of 5) and EACMV (1 of 5), indicating mixed infections of UCBSV with either or both cassava mosaic begomoviruses (CMB) in these samples. Cassava plants bearing mixed infections of UCBSV and these CMB showed more severe foliar symptoms (Fig. 1E) relative to plants with a single infection of UCBSV (Fig. 2A to D).

Determination and comparative analysis of complete genome sequence of UCBSV from Zambia. The genome of UCBSV isolate WP282 from Zambia was amplified as four pieces of overlapping DNA fragments using four pairs of newly designed primers (Table 1). Assembly of these sequence fragments resulted in a genome length of 9,050 nucleotides (nt) (GenBank accession number MG257787), representing the complete genome of Zambian UCBSV isolate WP282, minus the poly A tail. The WP282 sequence has a $5^{\prime}$ untranslated region (UTR) of $134 \mathrm{nt}$ and a 3' UTR of $207 \mathrm{nt}$ (excluding the poly A tail). The genome encodes a polyprotein 2,902 amino

Table 2. Incidences of foliar, stem, and root symptoms of cassava brown streak disease (CBSD) recorded in Zambia based on a diagnostic survey conducted in July 2017 in the northern districts of Chienge (Luapula province) and Kaputa (Northern province) of the country

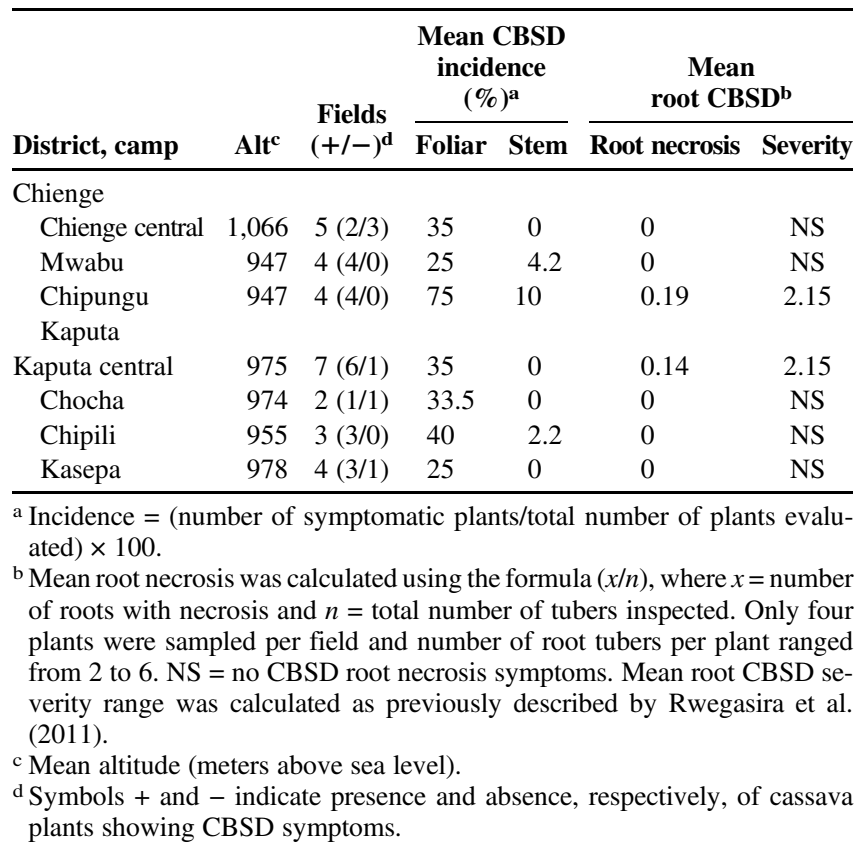


acids long, and homology-based prediction of its proteolytic cleavage sites revealed the expected 10 individual proteins for UCBSV isolates (Fig. 3). The SimPlot analysis of an alignment file of isolate WP282 (MG257787) together with 16 GenBank isolates of UCBSV revealed that it is more closely related to isolate MLB3 (FJ039520) from Tanzania and isolate Malawi (MF379362) from Malawi relative to other GenBank isolates (Fig. 3). In pairwise comparisons, the complete polyprotein sequence of isolate WP282 shared 94\% nucleotide and $96 \%$ amino acid identity levels with isolates MLB3 and Malawi, its closest relatives (Table 3 ). In contrast, polyprotein nucleotide and amino acid identity levels between isolate WP282 and the remaining GenBank isolates ranged from 86 to 88 and 92 to $94 \%$, respectively (Table 3). The levels of nucleotide and amino acid identities for the 10 encoded genes were similar to those of the polyprotein, with a few exceptions (Table 3). For instance, whereas isolate WP282 shared similar levels of nucleotide and amino acid identities with isolates
MLB3 and Malawi with respect to P1, P3, CI, NIa, and NIb proteins, contrasting results were obtained for the viral protein genome-linked (VPg), Ham1, and CP genes (Table 3). Although the VPg and CP genes of isolate WP282 were more identical to those of isolate MLB3, its Ham1 showed greater resemblance to that of isolate Malawi (Table 3). Overall, higher levels of Ham1 and CP nucleotide and amino acid identities were obtained for comparisons between isolate WP282 and GenBank isolates compared with other genes, indicating greater similarities between the $3^{\prime}$ termini genes of UCBSV relative to the $5^{\prime}$ termini genes.

Phylogenetic analysis and test for recombination. The Bayesian phylogenetic analyses confirmed the clustering of global isolates of CBSV and UCBSV into two major clades, one for each virus with isolate WP282 segregating into the UCBSV clade, as expected (Fig. 4). The same five UCBSV-specific subclades identified by Alicai et al. (2016) were recovered in this study, with isolate

\section{Query: UCBSV-ZM [MG257787]}

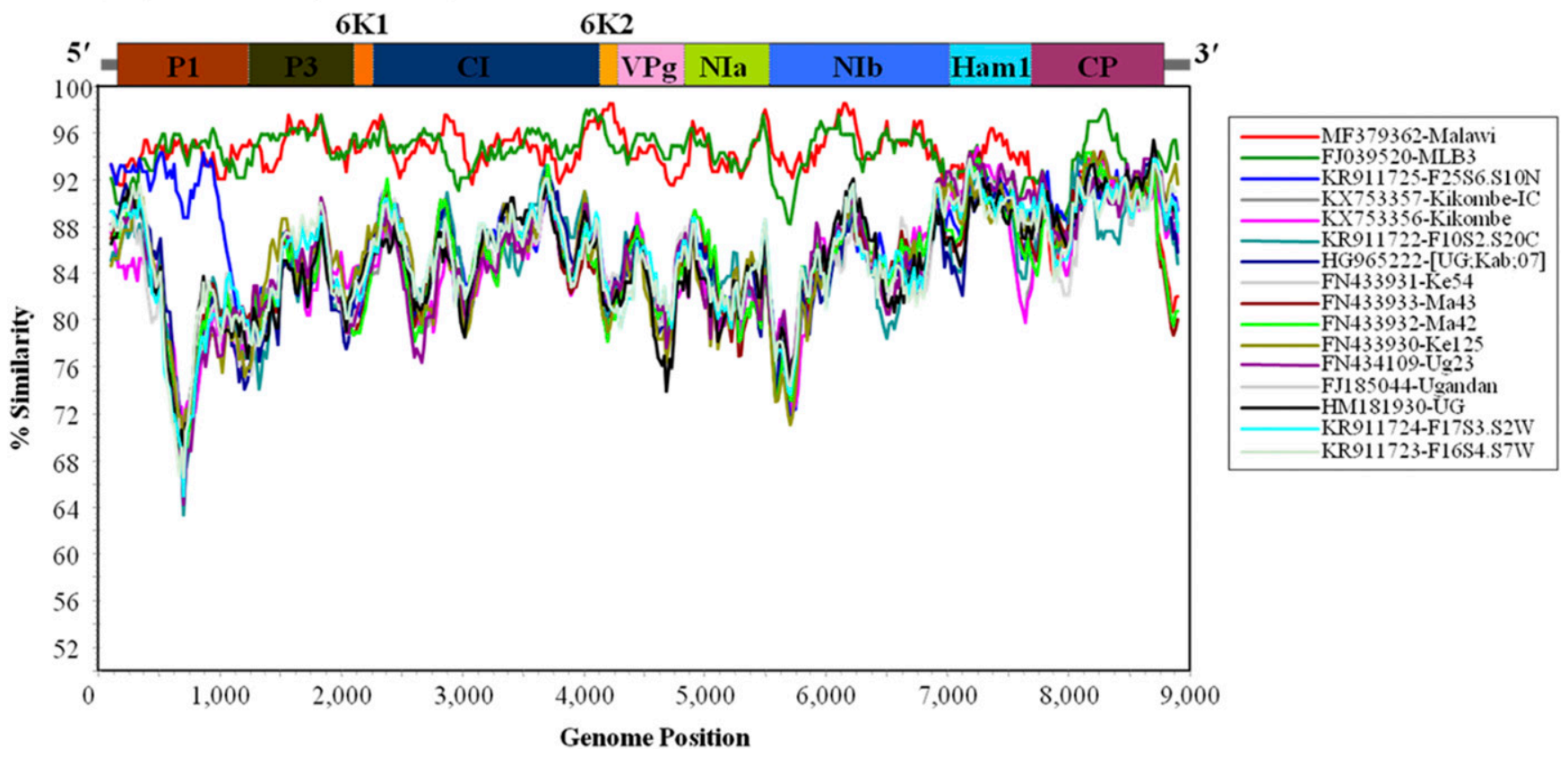

Fig. 3. Sliding-window Simplot graph showing genome-wide comparisons of isolate WP282 of Ugandan cassava brown streak virus (UCBSV) with other isolates of the virus. The Simplot graph was generated using multiple sequence alignments of UCBSV isolates with a window size of 200 nucleotides (nt) and a step size of 20 nt (Kimura two-parameter). A diagrammatic representation of the UCBSV genome with locations of the encoded proteins from $5^{\prime}$ to $3^{\prime}$ is shown above the graph. Details of genome organizations of UCBSV can be found in Mbanzibwa et al. (2011).

Table 3. Percent nucleotide/amino acid sequence identities between polyprotein and encoded genes of Zambian isolate WP282 of Ugandan cassava brown streak virus (MG257787) and global isolates of the virus

\begin{tabular}{|c|c|c|c|c|c|c|c|c|c|c|c|c|}
\hline Isolate & Accession & Polyprotein & P1 & P3 & $6 \mathrm{~K} 1$ & CI & $6 \mathrm{~K} 2$ & VPg & NIa & NIb & Ham1 & $\mathbf{C P}$ \\
\hline MLB3 & FJ039520 & $94 / 96$ & $94 / 94$ & $95 / 96$ & $96 / 96$ & $95 / 99$ & $97 / 98$ & $95 / 99$ & $95 / 97$ & $94 / 97$ & $92 / 92$ & $94 / 95$ \\
\hline Malawi & MF379362 & $94 / 96$ & $94 / 94$ & $95 / 96$ & $94 / 100$ & $95 / 99$ & $97 / 98$ & $94 / 96$ & $95 / 97$ & $95 / 97$ & $94 / 94$ & $91 / 94$ \\
\hline F25S6.S10N & KR911725 & $88 / 93$ & $92 / 93$ & $85 / 87$ & $81 / 96$ & $88 / 98$ & $83 / 94$ & $84 / 91$ & $85 / 95$ & $86 / 93$ & $90 / 89$ & $91 / 94$ \\
\hline Kikombe & KX753356 & $86 / 92$ & $83 / 88$ & $84 / 86$ & $85 / 96$ & $86 / 97$ & $85 / 96$ & $85 / 90$ & $84 / 92$ & $86 / 93$ & $90 / 89$ & $91 / 94$ \\
\hline Kikombe-IC & KX753357 & $86 / 92$ & $83 / 88$ & $85 / 86$ & $85 / 96$ & $86 / 97$ & $85 / 96$ & $85 / 90$ & $84 / 92$ & $86 / 93$ & $90 / 89$ & $91 / 94$ \\
\hline F10S2.S20C & KR911722 & $86 / 93$ & $83 / 88$ & $84 / 86$ & $85 / 96$ & $88 / 98$ & $82 / 96$ & $85 / 92$ & $85 / 96$ & $85 / 93$ & $89 / 88$ & $91 / 96$ \\
\hline Ma42 & FN433932 & $86 / 93$ & $84 / 90$ & $85 / 86$ & $79 / 92$ & $88 / 98$ & $82 / 92$ & $85 / 90$ & $85 / 96$ & $86 / 94$ & $90 / 91$ & $91 / 93$ \\
\hline Ma43 & FN433933 & $87 / 93$ & $84 / 90$ & $85 / 86$ & $80 / 94$ & $87 / 98$ & $82 / 92$ & $85 / 90$ & $85 / 96$ & $86 / 95$ & $90 / 92$ & $91 / 95$ \\
\hline Ke125 & FN433930 & $87 / 93$ & $83 / 88$ & $86 / 88$ & $84 / 96$ & $88 / 97$ & $81 / 96$ & $84 / 90$ & $85 / 94$ & $86 / 94$ & $90 / 91$ & $92 / 95$ \\
\hline $\mathrm{Ug} 23$ & FN434109 & $87 / 94$ & $83 / 89$ & $85 / 87$ & $81 / 96$ & $87 / 98$ & $84 / 96$ & $85 / 91$ & $85 / 95$ & $87 / 95$ & $92 / 91$ & $92 / 96$ \\
\hline Uganda:Nam & HM181930 & $87 / 93$ & $84 / 89$ & $84 / 86$ & $83 / 96$ & $88 / 97$ & $83 / 94$ & $83 / 90$ & $85 / 94$ & $86 / 93$ & $89 / 90$ & $91 / 95$ \\
\hline Ugandan & FJ185044 & $87 / 96$ & $84 / 89$ & $84 / 86$ & $83 / 96$ & $88 / 97$ & $83 / 94$ & $83 / 90$ & $85 / 94$ & $86 / 93$ & $89 / 90$ & $91 / 95$ \\
\hline F16S4.S7W & KR911723 & $87 / 94$ & $84 / 90$ & $85 / 87$ & $83 / 98$ & $88 / 98$ & $85 / 96$ & $84 / 91$ & $85 / 94$ & $86 / 95$ & $90 / 91$ & $90 / 95$ \\
\hline F17S3.S2W & KR911724 & $87 / 93$ & $84 / 90$ & $85 / 87$ & $83 / 96$ & $88 / 98$ & $85 / 96$ & $85 / 91$ & $85 / 94$ & $86 / 95$ & $90 / 91$ & $91 / 95$ \\
\hline UG:Kab & HG965222 & $87 / 93$ & $84 / 90$ & $84 / 86$ & $83 / 96$ & $88 / 98$ & $85 / 96$ & $85 / 90$ & $86 / 95$ & $85 / 94$ & $89 / 89$ & $91 / 95$ \\
\hline Ke54 & FN433931 & $87 / 93$ & $83 / 89$ & $84 / 87$ & $81 / 96$ & $88 / 97$ & $85 / 96$ & $85 / 91$ & $85 / 95$ & $86 / 95$ & $91 / 91$ & $90 / 93$ \\
\hline
\end{tabular}


WP282 segregating into clade $\mathrm{C}$ along with isolates UCBSV TZ_MLB3_(FJ039520), UCBSV_MA_43_(FN433933), and UCBSV_TZ_Tan_23_(KR108839) (Fig. 4). These results confirm the results of Alicai et al. (2016) that members of UCBSV clade C (WP282, MLB3, MA_43, and Tan_23) represent a unique UCBSV lineage. A reticulate (nontree-like) network was detected when the UCBSV sequence alignment file was subjected to analysis with the Neighbor-Net method of the SplitsTree program, v4.10 (Fig. 5). Further analysis with the different RDP4-implemented programs revealed two putative recombination events involving isolate WP282 (Table 4) in addition to events involving other UCBSV isolates, as previously reported (Alicai et al. 2016; Mbanzibwa et al. 2011; Ndunguru et al. 2015). Results from this analysis suggest that isolate WP282 arose potentially as a consequence of genetic recombination.

\section{Discussion}

CBSD and CMD are no doubt the most serious constraints to sustainable production of cassava in sub-Saharan African countries. Unlike CMD, which is endemic in all sub-Saharan African cassavaproducing countries, the geographical distribution of CBSD and its causal viruses have thus far been limited largely to the southeastern axis of the African continent. At present, there are confirmed reports of CBSD occurrence in nine countries, including Uganda, Kenya, Malawi, Tanzania, Mozambique, Rwanda, Burundi, Democratic Republic of Congo, and the Indian Oceanic island of Mayotte (Legg et al. 2015). Given the proximity of Zambia to some of these countries, including the fact that it shares extensive land borders with Malawi and the Democratic Republic of Congo (Fig. 1), it seemed inevitable that CBSD would eventually spread into Zambia. Consequently, CBSD and its causal viruses are considered priorities in surveillance efforts by scientists from the Zambian Agricultural Research Institute and the International Institute of Tropical Agriculture. Interestingly, despite extensive surveys (Chikoti et al. 2013, 2015), CBSD and its causal viruses have not been found in Zambia prior to this study, thus prompting the current survey effort. With the mean incidences of approximately $32 \%$ across approximately $79 \%$ of farmers' fields (23 of 29) in the surveyed districts, it is evident that CBSD is relatively widespread in both Chienge (Luapula province) and Kaputa (Northern province) districts of Zambia. In these fields, CBSD was documented on commonly grown cassava landraces and on the cultivar that farmers referred to as Research. Due to the annual growth pattern of cassava, it is difficult to estimate how long CBSD had been present but an approximately 79\% (23 of 29) prevalence and approximately $32 \%$ mean disease incidence across surveyed fields and all six encountered cassava cultivars would suggest that local spread has occurred over time, albeit at low rates. The only logical explanation for CBSD incursion into Zambia is that the disease was probably initially introduced inadvertently via farmer-to-farmer exchange of contaminated cassava planting material rather than by the whitefly vector. Subsequently, the combination of a low whitefly population in most of the cassava-growing provinces in Zambia (Chikoti et al. 2015) and low B. tabaci transmission efficiency of CBSV (Maruthi et al. 2005) contributed to a limited CBSD spread encountered during the survey. This is in addition to the universally accepted view that long-distance spread of whitefly-transmitted viruses is caused by human movement of infected planting materials from regions where disease occurs to new areas (Legg 1999; Mbewe et al. 2015).

The detection of UCBSV alone from all 92 symptomatic plants sampled in this study supports the view that it is more widespread than CBSV (Bigirimana et al. 2011; Mbanzibwa et al. 2011; Mbewe et al. 2015; Michel et al. 2016; Mulimbi et al. 2012). The exact reasons for the widespread nature of UCBSV relative to CBSV remain unclear, especially against the background that isolates of the latter virus are more virulent than those of the former (Alicai et al. 2016; Ogwok et al. 2015). Although initial reports point to an altitudedependent prevalence of CBSV and UCBSV (Alicai et al. 2007; Mbanzibwa et al. 2009), an altitude-independent occurrence of both viruses has also been reported recently (Alicai et al. 2016; Ndunguru et al. 2015). Hence, studies of the comparative epidemiology of both viruses and the relative ability of the whitefly vector to acquire and

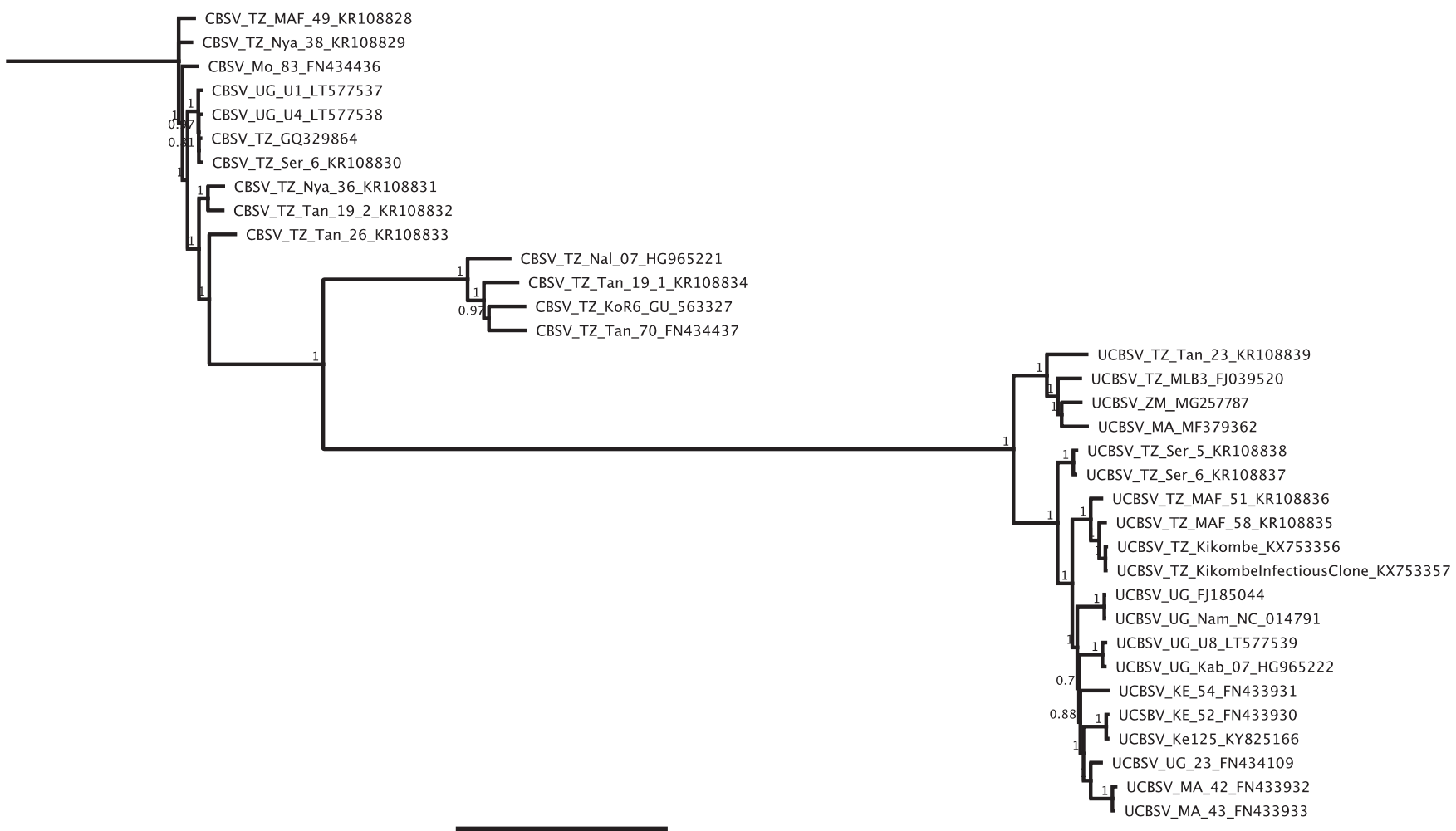

0.3

Fig. 4. Bayesian analysis depicting evolutionary relationships between Ugandan cassava brown streak virus (UCBSV) isolate WP282 from Zambia and global isolates of the virus and Cassava brown streak virus (CBSV). The analysis was conducted using ExaBayes, version 1.4.1 (Aberer et al. 2014), essentially as described in Ndunguru et al. (2015). 
transmit them are warranted in order to better understand factors responsible for the widespread nature of UCBSV than CBSV.

The majority (87 of 92) of the symptomatic UCBSV-positive cassava plants were singly infected with the virus and exhibited a mild symptom phenotype (Fig. 2A to D), in agreement with previous reports (Legg et al. 2015; Mbanzibwa et al. 2009; Ogwok et al. 2015). These results indicated the prevalence of single infection of UCBSV in the surveyed fields. However, five symptomatic plants of the landraces Chibungabunga and Kalilanshindo from three cassava fields located in Kaputa district showed severe symptoms (Fig. 2E). Further evaluation of these plants showed mixed infections of UCBSV with ACMV or EACMV, thus suggestive of synergism between the coinfecting viruses. Root and stem symptoms (Fig. 2F and $G$ ) were also observed in some of the disease-affected plants in the two districts (Chienge and Kaputa), consistent with symptoms documented in previous studies (Nichols 1950; Mbewe et al. 2015; Patil and Fauquet 2014) and indicating that these phenotypes directly correlated to negative impacts of CBSD are also present under Zambian growing conditions. However, foliar symptoms predominated in all 23 CBSD-affected fields in agreement with previous reports which indicated that foliar CBSD symptoms are the most common and streaks on stems and root necrosis are irregular in cassava plants naturally infected with CBSD causal viruses (Alicai et al. 2016; Mbewe et al. 2015; Ndunguru et al. 2015; Ogwok et al. 2010).

The genome characterization of isolate WP282 from Zambia and its clustering pattern (Fig. 4) further support the distinct nature of the UCBSV clade $\mathrm{C}$ isolates identified in a recent study (Ndunguru et al. 2015; Alicai et al. 2016). In this clade, isolate WP282 showed contrasting patterns of gene-specific sequence similarities and differences with other members, indicating its distinctness as a sequence variant of UCBSV. Interestingly, the observed contrasting patterns of sequence similarities between WP282 and its closest relatives occurred in the $3^{\prime}$ distal Ham 1 and CP genes, whereas similar levels of sequence similarities were observed for other regions of the genome (Table 3; Fig. 3). These observations point to potential genetic exchanges occurring among natural populations of UCBSV, perhaps as a consequence of an expansion in its geographical distribution (Mbanzibwa et al. 2011). Notably, the sequences of recently generated UCBSV infectious clones Kikombe (KX753356) and Kikombe-IC (KX753357) (S. Nanyiti, unpublished) differ considerably from those of clade $\mathrm{C}$ isolates (Table 3; Figs. 3 and 4); hence, there may be a need to generate additional clade-specific infectious clones for use by breeders and scientists in breeding and reverse genetics studies.

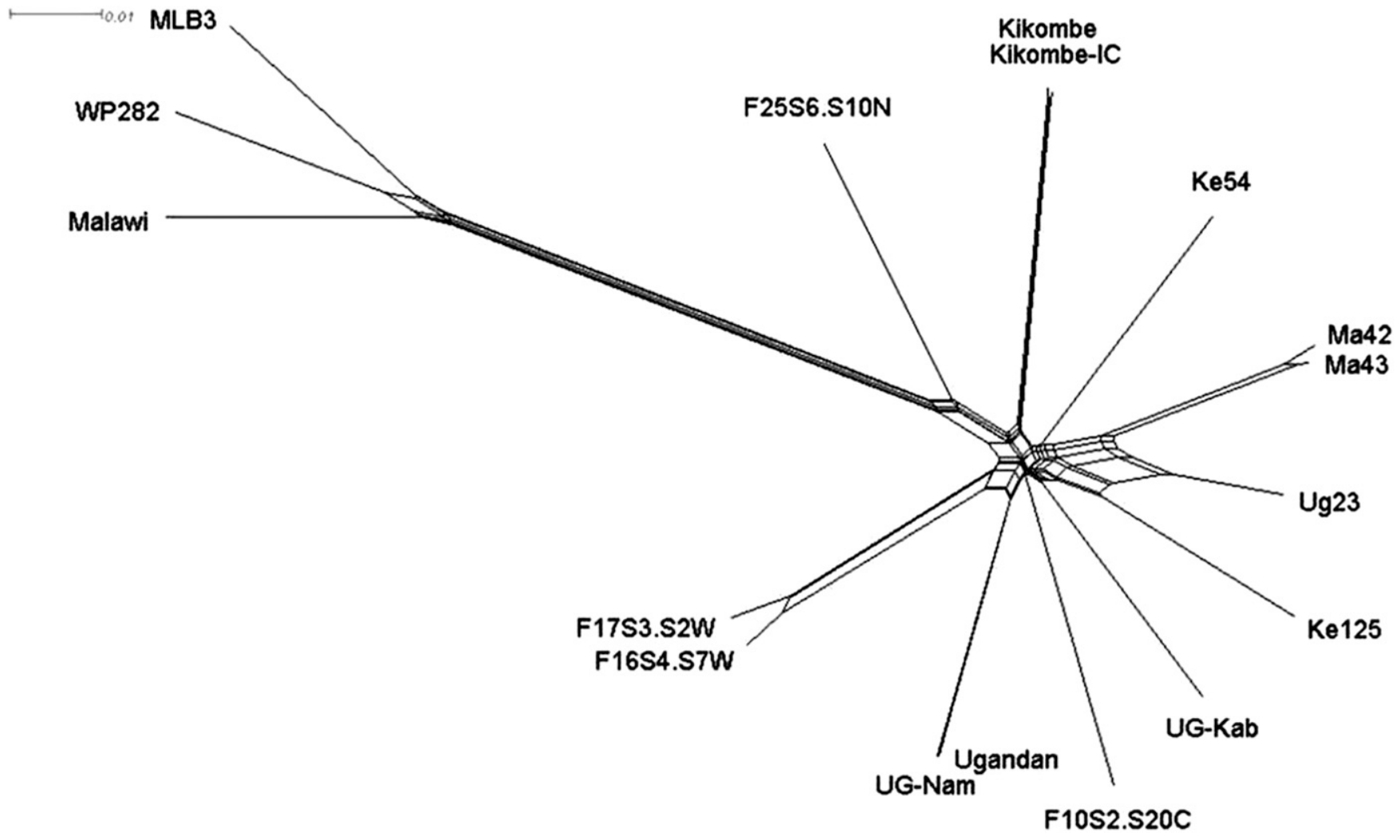

Fig. 5. SplitsTree reticulate (nontree-like) networks analyses of complete polyprotein sequences of Ugandan cassava brown streak virus. The network analyses were performed using the Neighbor-Net method as implemented in SplitsTree v4.10 (Huson and Bryant 2006).

Table 4. Putative recombination events involving Ugandan cassava brown streak virus isolate WP282 (MG257787)

\begin{tabular}{|c|c|c|c|c|c|}
\hline \multirow[b]{2}{*}{ Isolate $^{b}$} & \multirow[b]{2}{*}{ Accession $^{\mathrm{c}}$} & \multicolumn{2}{|c|}{ 'Parent-like' isolates ${ }^{\mathbf{a}}$} & \multirow[b]{2}{*}{ Method $^{d}$} & \multirow[b]{2}{*}{$P$ value } \\
\hline & & Major & Minor & & \\
\hline WP282 & $6919(\mathrm{NIb}), 7772(\mathrm{CP})$ & Unknown & Ma43 (90\%) & $\mathrm{M}, \mathbf{C}, 3 \mathrm{~S}$ & $7.514 \times 10^{-04}$ \\
\hline Malawi & 7796 (CP), 31 (P1) & WP282 (95\%) & Ma43 (98\%) & $\mathrm{R}, \mathrm{G}, \mathbf{B}, \mathrm{M}, \mathrm{C}, \mathrm{S}, 3 \mathrm{~S}$ & $5.645 \times 10^{-35}$ \\
\hline
\end{tabular}

a Percent similarity value shared by the putative recombinant with each parent-like isolate is shown in parenthesis.

${ }^{b}$ Putative recombinant isolate.

${ }^{\mathrm{c}}$ Genomic regions corresponding to the putative recombination breakpoints are shown in parenthesis.

${ }^{\mathrm{d}}$ The different recombination detection used in the RDP4 analyses are $\mathrm{R}=\mathrm{RDP}, \mathrm{G}=\mathrm{GENECONV}, \mathrm{B}=\mathrm{BOOTSCAN}, \mathrm{M}=\mathrm{MAXCHI}, \mathrm{C}=\mathrm{CHIMAERA}, \mathrm{S}=$ SISCAN, and 3S = 3SEQ. Only events supported by at least three of the seven RDP4-implemented methods (Martin et al. 2015) are reported.

${ }^{\mathrm{e}}$ Support probability $(P$ value) for the method in bold is shown. 
A pertinent question of interest to national and regional regulatory agencies is regarding the possible route of spread of CBSD into Zambia. The relatively high level of similarity of isolate WP282 with UCBSV isolates from Malawi and Tanzania (Table 3; Figs. 3 and 4) suggests possible incursion of the disease from either country into Zambia. However, recent intensive and extensive surveys, conducted especially in farmer's fields along the long border of Zambia with Malawi, reported the absence of CBSD in these areas (Chikoti et al. 2013, 2015). Therefore, it is logical to propose that isolate WP282 was probably introduced into Zambia from Tanzania. The support for this inference is found in higher levels of sequence similarities obtained between isolate WP282 and Tanzanian isolate MLB3 in 9 of 10 genes compared with 8 of 10 genes with isolate Malawi (Table 3). Interestingly, isolate MLB3 was sourced from the Kagera region of northwestern Tanzania, which is bordered to the west by Lake Tanganyika, a freshwater lake that supports commerce and human movement across the countries Tanzania, Democratic Republic of the Congo, Burundi, and Zambia. It is also conceivable that UCBSV introduction into Zambia came from the Democratic Republic of Congo, with whom the surveyed districts share a land border (Fig. 1). However, no genomic data are available from the Democratic Republic of Congo; hence, future studies are needed to help us track the true origin of UCBSV introduction into Zambia. Regardless, there exists a very high risk of CBSD spread postintroduction to other cassavagrowing provinces of Zambia via movement of infected stems or whiteflies if urgent exclusionary measures are not taken by relevant regulatory agencies in the country. Therefore, our results point to the need to strengthen phytosanitary programs and intensify farmer extension and outreach efforts in the region to stem the tide of disease spread via movement of plant germplasm.

In conclusion, we have detected the occurrence of CBSD for the first time in Zambia and the association of a sequence variant of UCBSV with the disease in affected fields. Efforts have been initiated by the Zambian Agriculture Research Institute to destroy cassava plants in all affected fields to avert further spread inland to cassava fields in the seven major cassava producing provinces of the country.

\section{Acknowledgments}

We thank the management of the Texas A\&M AgriLife Research and Extension Center, Weslaco for facility support and A. Zongoma (Ahmadu Bello University, Zaria, Nigeria) for technical assistance.

\section{Literature Cited}

Abarshi, M. M., Mohammed, I. U., Jeremiah, S. C., Legg, J. P., Lava Kumar, P., Hillocks, R. J., and Maruthi, M. N. 2012. Multiplex RT-PCR assays for the simultaneous detection of both RNA and DNA viruses infecting cassava and the common occurrence of mixed infections by two cassava brown streak viruses in East Africa. J. Virol. Methods 179:176-184.

Aberer, A. J., Kobert, K., and Stamatakis, A. 2014. ExaBayes: Massively parallel Bayesian tree inference for the whole-genome era. Mol. Biol. Evol. 31: 2553-2556.

Alabi, O. J., Al Rwahnih, M., Karthikeyan, G., Poojari, S., Fuchs, M., Rowhani, A., and Naidu, R. A. 2011. Grapevine leafroll-associated virus 1 occurs as genetically diverse populations. Phytopathology 101:1446-1456.

Alabi, O. J., Mulenga, R. M., and Legg, J. P. 2015. Cassava mosaic. Pages 56-72 in: Virus Diseases of Tropical and Subtropical Crops. P. Tennant and G. Fermin, eds. CABI International, Wallingford, Oxfordshire, UK.

Alicai, T., Ndunguru, J., Sseruwagi, P., Tairo, F., Okao-Okuja, G., Nanvubya, R., Kiiza, L., Kubatko, L., Kehoe, M., and Boykin, M. L. 2016. Cassava brown streak virus has a rapidly evolving genome: Implications for virus speciation, variability, diagnosis and host resistance. Sci. Rep. 6: Article 36164.

Alicai, T., Omongo, C. A., Maruthi, M. N., Hillocks, R. J., Baguma, Y., Kawuki, R., Bua, A., Otim-Nape, G. W., and Colvin, J. 2007. Re-emergence of cassava brown streak disease in Uganda. Plant Dis. 91:24-29.

Ateka, E., Alicai, T., Ndunguru, J., Tairo, F., Sseruwagi, P., Kiarie, S., Makori, T., Kehoe, M. A., and Boykin, L. M. 2017. Unusual occurrence of a DAG motif in the ipomovirus Cassava brown streak virus and implications for its vector transmission. PLoS One 12:e0187883.

Bigirimana, S., Barumbanze, P., Ndayihanzamaso, P., Shirima, R., and Legg, J. P. 2011. First report of cassava brown streak disease and associated Ugandan cassava brown streak virus in Burundi. New Dis. Rep. 24:26.

Chikoti, P. C., Ndunguru, J., Melis, R., Tairo, F., Shanahan, P., and Sseruwagi, P. 2013. Cassava mosaic disease and associated viruses in Zambia: Occurrence and distribution. Int. J. Pest Manage. 59:63-72.
Chikoti, P. C., Tembo, M., Chisola, M., Ntawuruhunga, P., and Ndunguru, J. 2015. Status of cassava mosaic disease and whitefly population in Zambia. Afr. J. Biotechnol. 14:2539-2546.

Hall, T. A. 1999. BioEdit: A user-friendly biological sequence alignment editor and analysis program for Windows 95/98/NT. Nucleic Acids Symp. Ser. 41:95-98.

Hillocks, R. J., Thresh, J. M., Tomas, J., Botao, M., Macia, R., and Zavier, R. 2002. Cassava brown streak disease in northern Mozambique. Int. J. Pest Manage. 48:178-182.

Huson, D. H., and Bryant, D. 2006. Application of phylogenetic networks in evolutionary studies. Mol. Biol. Evol. 23:254-267.

Legg, J. P. 1999. Emergence, spread and strategies for controlling the pandemic of cassava mosaic virus disease in east and central Africa. Crop Prot. 18: 627-637.

Legg, J. P., Lava Kumar, P., Makeshkumar, T., Tripathi, L., Ferguson, M., Kanju, E., Ntawuruhunga, P., and Cuellar, W. 2015. Cassava virus diseases: Biology, epidemiology, and management. Pages 85-142 in: Control of Plant Virus Diseases - Vegetatively-Propagated Crops. G. Loebenstein and N. I. Katis, eds. Advances in Virus Research, Vol. 91. Elsevier Inc., Kidlington, Oxford, UK.

Lole, K. S., Bollinger, R. C., Paranjape, R. S., Gadkari, D., Kulkarni, S. S., Novak, N. G., Ingersoll, R., Sheppard, H. W., and Ray, S. C. 1999. Full-length human immunodeficiency virus type 1 genomes from subtype $\mathrm{C}$-infected seroconverters in India, with evidence of intersubtype recombination. J. Virol. 73:152-160.

Martin, D. P., Murrell, B., Golden, M., Khoosal, A., and Muhire, B. 2015. RDP4 Detection and analysis of recombination patterns in virus genomes. Virus Evol. 1:1-5

Maruthi, M. N., Hillocks, R. J., Mtunda, K., Raya, M. D., Muhanna, M., Kiozia, H., Rekha, A. R., Colvin, J., and Thresh, J. M. 2005. Transmission of Cassava brown streak virus by Bemisia tabaci (Gennadius). J. Phytopathol. 153:307-312.

Mbanzibwa, D. R., Tian, Y. P., Tugume, A. K., Mukasa, S. B., Tairo, F., Kyamanywa, S., Kullaya, A., and Valkonen, J. P. T. 2009. Genetically distinct strains of Cassava brown streak virus in the Lake Victoria basin and the Indian Ocean coastal area of East Africa. Arch. Virol. 154:353-359.

Mbanzibwa, D. R., Tian, Y. P., Tugume, A. K., Patil, B. L., Yadav, J. S., Bagewadi, B., Abarshi, M. M., Alicai, T., Changade, W., Mkumbira, J., Muli, M. B., Mukasa, S. B., Tairo, F., Baguma, Y., Kyamanywa, S., Kullaya, A., Maruthi, M. N., Fauquet, C. M., and Valkonen, J. P. T. 2011. Evolution of cassava brown streak disease-associated viruses. J. Gen. Virol. 92:974-987.

Mbewe, W., Kumar, P. L., Changadeya, W., Ntawuruhunga, P., and Legg, J. 2015. Diversity, distribution and effects on cassava cultivars of cassava brown streak viruses in Malawi. J. Phytopathol. 163:433-443.

Michel, R.-C., David, T., Thomas, C., Charles, J., Delphine, M., Katia, J., Liachourutu, A. K. A., Bruno, H., Bernard, R., Legg, J. P., and Lett, J.-M. 2016. Occurrence of cassava brown streak disease and associated Ugandan cassava brown streak virus in Mayottee Island (Mozambique Channel). Online publication. Electronic Proceedings of the World Congress on Root and Tuber Crops. WCRTC, Nanning, Guangxi, China. http://agritrop.cirad.fr/583318/

Mulenga, R. M., Legg, J. P., Ndunguru, J., Chikoti, P. C., Miano, D. W., Mutitu, W. E., and Alabi, O. J. 2016. Survey, molecular detection, and characterization of geminiviruses associated with cassava mosaic disease in Zambia. Plant Dis. 100:1379-1387.

Mulimbi, W., Phemba, X., Assumani, B., Kasereka, P., Muyisa, S., Ugentho, H., Reeder, R., Legg, J. P., Laurenson, L., Weekes, R., and Thom, F. E. F. 2012. First report of Ugandan cassava brown streak virus on cassava in Democratic Republic of Congo. New Dis. Rep. 26:11.

Ndunguru, J., Legg, J. P., Aveling, T. A. S., Thompson, G., and Fauquet, C. M. 2005. Molecular biodiversity of cassava begomoviruses in Tanzania: evolution of cassava geminiviruses in Africa and evidence for East Africa being a center of diversity of cassava geminiviruses. Virol. J. 2:21.

Ndunguru, J., Sseruwagi, P., Tairo, F., Stomeo, F., Maina, S., Djinkeng, A., Kehoe, M., and Boykin, M. L. 2015. Analyses of twelve new whole genome sequences of cassava brown streak viruses and Ugandan cassava brown streak viruses from East Africa: Diversity, supercomputing and evidence for further speciation. PLoS One 10:e0139321.

Nichols, R. F. J. 1950. The brown streak disease of cassava: Distribution, climatic effects and diagnostic symptoms. East Afr. Agric. J. 15:154-160.

Ogwok, E., Alicai, T., Rey, M. E. C., Beyene, G., and Taylor, N. J. 2015 Distribution and accumulation of cassava brown streak viruses within infected cassava (Manihot esculenta) plants. Plant Pathol. 64:1235-1246.

Ogwok, E., Patil, B. L., Alicai, T., and Fauquet, C. M. 2010. Transmission studies with Cassava brown streak Uganda virus (Potyviridae: Ipomovirus) and its interaction with abiotic and biotic factors in Nicotiana benthamiana. J. Virol. Methods 169:296-304.

Patil, B. L., and Fauquet, C. M. 2014. Light intensity and temperature affect systemic spread of silencing signal in transient agroinfiltration studies. Mol Plant Pathol. 16:484-494.

Patil, B. L., Ogwok, E., Wagaba, H., Mohammed, I. U., Yadav, J. S., Bagewadi, B., Taylor, N. J., Kreuze, J. F., Maruthi, M. N., Alicai, T., and Fauquet, C. M. 2011. RNAi-mediated resistance to diverse isolates belonging to two virus species involved in cassava brown streak disease. Mol. Plant Pathol. 12:31-41.

Pita, J. S., Fondong, V. N., Sangare, A., Otim-Nape, G. W., Ogwal, S., and Fauquet, C. M. 2001. Recombination, pseudorecombination and synergism of geminiviruses are determinant keys to the epidemic of severe cassava mosaic disease in Uganda. J. Gen. Virol. 82:655-665. 
Rajabu, C. A. 2013. Development and evaluation of efficient diagnostic tools for cassava mosaic and cassava brown streak diseases. M.Sc. thesis, The University of Witwatersrand, Johannesburg Republic of South Africa.

Rwegasira, G. M., Momanyi, G., Rey, M. E. C., Kahwa, G., and Legg, J. P. 2011. Widespread occurrence and diversity of Cassava brown streak virus (Potyviridae: Ipomovirus) in Tanzania. Phytopathology 101:1159-1167.

Sseruwagi, P., Sserubombwe, W. S., Legg, J. P., Ndunguru, J., and Thresh, J. M. 2004. Methods of surveying the incidence and severity of cassava mosaic disease and whitefly vector populations on cassava in Africa: A review. Virus Res. 100:129-142.

Storey, H. H. 1936. Virus diseases of East African plants. VI-A progress report on studies of the disease of cassava. East Afr. Agric. J. 2:34-39.
Thottappilly, G., Thresh, J. M., Calvert, L. A., and Winter, S. 2003. Cassava. Pages 107-165 in: Virus and Virus-Like Diseases of Major Crops in Developing Countries. G. Loebenstein and G. Thottappilly, eds. Springer, Dordrecht, The Netherlands.

Tugume, A. K., Cuéllar, W. J., Mukasa, S. B., and Valkonen, J. P. T. 2010 Molecular genetic analysis of virus isolates from wild and cultivated plants demonstrates that East Africa is a hotspot for the evolution and diversification of Sweet potato feathery mottle virus. Mol. Ecol. 19:3139-3156.

Winter, S., Koerbler, M., Stein, B., Pietruszka, A., Paape, M., and Butgereitt, A. 2010. Analysis of cassava brown streak viruses reveals the presence of distinct virus species causing cassava brown streak disease in East Africa. J Gen. Virol. 91:1365-1372. 